\title{
O tempo dos processos de adoção: análise de alguns fatores determinantes
}

\section{The time of the adoption processes: analysis of some determining factors}

\author{
Livia Copelli Copatti ${ }^{l}$
} Simone Franceschi ${ }^{2}$

\section{RESUMO:}

Para habilitação à adoção há uma série de expectativas que permeiam o imaginário dos futuros pais, sendo que uma das principais é o tempo que transcorrerá desde o momento da habilitação até serem chamados para a adoção. Assim, o presente trabalho traz como objetivo principal a verificação das motivações temporais dos processos de adoção, utilizando para tanto o método dedutivo. Para o desenvolvimento da pesquisa, faz-se necessária, inicialmente, uma revisão bibliográfica sobre os assuntos que dizem respeito ao objetivo geral, quais sejam, a adoção e a duração razoável do processo. O trabalho está estruturado, inicialmente, com a conceituação e contextualização da adoção e da destituição do poder familiar e os requisitos para que ocorra a adoção, em conformidade com o previsto no Estatuto da Criança e do Adolescente. Em um segundo momento trata-se sobre o tempo de duração dos processos no Poder Judiciário brasileiro, sendo que, devido a crítica que existe em torno ao assunto, optouse pelo estudo de dois dos direitos fundamentais elencados na Constituição Federal de 1988, qual seja, o devido processo legal e a razoável duração dos processos. E por fim, a pesquisa centra-se no seu objetivo principal, qual seja, a análise sobre as motivações temporais dos processos de adoção, analisando-se dados do Cadastro Nacional de Adoção e referenciais bibliográficos. Os resultados da pesquisa apontam que as preferências dos adotantes e a demora no processo de destituição do poder familiar são os principais fatores que impactam no longo tempo de tramitação dos processos de adoção.

Palavras-chaves: Criança e adolescente; Adoção; Razoável duração do processo.

\footnotetext{
${ }^{1}$ Doutora em Direito pela Universidade Estácio de Sá - Rio de Janeiro. Mestre em Direito pela Universidade de Santa Cruz do Sul - Rio Grande do Sul. Bacharel em Direito pela Universidade Regional Integrada do Alto Uruguai e Missões - URI - Campus Erechim. Docente na Faculdade Meridional - IMED - Passo Fundo. Advogada. E-mail: livia.copatti@imed.edu.br ou livia_dto@yahoo.com.br.

2 Graduada em Direito pela Faculdade Meridional - IMED - Passo Fundo. E-mail: monefranceschi@hotmail.com.
} 


\begin{abstract}
:
To qualify for adoption there are a series of expectations that permeate the imaginary of the future parents, and one of the main is the time that will run from the time of habilitation until they are called for adoption. Thus, the main objective of the present work is to verify the temporal motivations of the adoption processes, using the deductive method. For the development of the research, it is necessary, initially, a bibliographical review on the subjects that concern the general objective, that is, the adoption and the reasonable length of the process. The work is structured, initially, with the conceptualization and contextualization of the adoption and the dismissal of family power and the requirements for adoption to take place, in accordance with the provisions of the Statute of the Child and Adolescent. In a second moment, it is a question of the duration of the proceedings in the Brazilian Judiciary, being that, due to the criticism that exists around the subject, it was opted for the study of two of the fundamental rights listed in the Federal Constitution of 1988, which due process and the reasonable duration of proceedings. Finally, the research focuses on its main objective, that is, the analysis on the temporal motivations of the adoption processes, analyzing data from the National Register of Adoption and bibliographic references. The results of the research indicate that the preferences of the adopters and the delay in the process of destitution of family power are the main factors that have an impact on the long process of adoption processes.
\end{abstract}

Keywords: Child and teenager; Adoption; Reasonable length of process 


\section{INTRODUÇÃO}

A adoção trata-se de um dos institutos de extrema importância no cenário brasileiro atual, e de maneira especial, o tema possui grande importância devido ao fato de poder vivenciar casos reais de adoção, podendo ter a experiência de presenciar os sentimentos envolvidos, tanto por parte dos adotantes, quanto por parte de quem está sendo adotado, bem como da triste realidade dos processos que envolve a perda do poder familiar, que de modo geral sempre trazem um desgaste emocional significativo na vida das crianças e adolescentes envolvidos.

De modo especial, a presente pesquisa está estruturada e desenvolve-se pelo fato de poder analisar os processos de adoção, sua duração e todos os movimentos que os mesmos fazem desde seu início (data da propositura) até seu término (data do trânsito em julgado e baixa).

Porém, antes de adentrar na análise das motivações temporais que impactam no processo de adoção de crianças e adolescentes, necessário se faz compreender o próprio sistema do processo de adoção e seu instituto. Como se verá a seguir, a adoção é um dos sistemas mais antigos de existem e fez parte do costume de muitos povos. A principal finalidade da adoção é poder oferecer um ambiente familiar favorável ao desenvolvimento de uma criança e adolescente, que, por dado motivo, ficou privada de sua família biológica. $\mathrm{Ou}$ seja, com a adoção, busca-se uma família que possa dar amor, afeto e cuidado àquela criança ou àquele adolescente que se encontra amparado temporariamente pelo Estado.

O processo de adoção sempre terá como premissa básica e fundamental o melhor interesse da criança e do adolescente. De acordo com o Estatuto da Criança e do Adolescente (ECA), o direito desses últimos é permanecer no seio da família biológica a fim de assegurar o direito constitucional da convivência familiar e comunitária, sendo que a criança e o adolescente somente serão retirados de sua família biológica quando o juiz concluir ser impossível a manutenção no seio familiar de origem. Portanto, a adoção trata-se de uma medida excepcional.

Nesse sentido busca-se analisar, não só o instituto da adoção, mas todas as suas fases processuais, a fim de evidenciar qual o motivo da morosidade dos processos de adoção no Brasil. Nesse sentido, procurar-se-á estudar e trazer para a presente pesquisa dois dos direitos fundamentais elencados na Suprema Carta, a Constituição Federal de 1988, sejam eles o 
devido processo legal e a razoável duração do processo, dois institutos de suma importância na presente pesquisa e que podem direcionar para as conclusões do trabalho.

Ao final, espera-se ser capaz de oferecer possíveis soluções para tornar o tempo dos processos de adoção o menor possível, sempre levando em conta o melhor interesse da criança e do adolescente, bem como quanto ao aspecto de que a adoção traga reais vantagens para os infantes, princípios estes precursores nas relações que envolvam crianças e adolescentes.

\section{OS ASPECTOS DOS PROCESSOS DE ADOÇÃO}

O processo de adoção no Brasil, desde a Constituição de 1988, é visto como medida de proteção à criança e ao adolescente. Por motivos muito além dos interesses pertinentes dos adultos envolvidos, o processo de adoção prioriza o bem-estar das crianças e adolescentes envolvidos.

Definiu o Estatuto da Criança e do Adolescente - ECA - como sendo adoção o meio pelo qual alguém recebe o caráter de filho (a) natural, com os mesmos direitos e deveres, bem como ao direito sucessório, desligando-o de qualquer vínculo com os pais e/ou parentes biológicos, ressalvando nos casos de impedimentos matrimoniais (FONSECA, 2011, p. 140).

Nesse sentido, o ato de adotar trata-se de uma escolha clara e consciente, sendo ela concluída mediante uma decisão do Poder Judiciário, através da figura do juiz, a partir da qual uma criança ou adolescente torna-se irrevogavelmente filho (a) de alguém.

De acordo com o ECA, o direito da criança e do adolescente é permanecer no seio da família biológica a fim de assegurar o direito constitucional da convivência familiar e comunitária, sendo a criança e o adolescente retirado de sua família biológica somente quando o juiz concluir ser impossível a sua manutenção no seio familiar biológico. Portanto, a adoção trata-se de uma medida excepcional (BRASIL, 1990).

Observar-se-á, na sequência, os pontos determinantes para que ocorra a adoção de crianças e adolescentes, desde os requisitos a serem observados até o processo de adoção e a sua tramitação.A adoção é considerada um dos institutos mais antigos do direito, bem como faz parte dos costumes de muitos povos. A principal finalidade da adoção é poder oferecer um ambiente familiar favorável ao desenvolvimento de uma criança e adolescente, que, por dado motivo, ficou privada de sua família biológica (GRANATO, 2010, p. 29). 
Ainda, de acordo com Granato (2010, p. 29), a adoção não pode ser compreendida como uma maneira ou forma de "ter pena" com relação a um infante, ou mesmo, resolver situações de conflitos entre casais, bem como não pode servir de remédio para a esterilidade ou mesmo ser conforto para a solidão. $\mathrm{O}$ que se pretende com a adoção é atender as reais necessidades da criança e do adolescente, dando-lhe uma família, onde possa se sentir acolhida, protegida, segura e amada.

É inconcebível conceder a adoção a alguém que não tenha como principal pressuposto o bem-estar do adotando. Muitas vezes as pessoas procuram o instituto da adoção pelo simples fato de estarem buscando alguém que lhes faça companhia, por medo de acabarem sozinhas sem alguém que as zele, sendo que a adoção jamais poderá ser realizada para esse fim. A adoção busca sempre a proteção das crianças e adolescentes, não devendo ser vista como forma de acabar com a solidão de alguém.

Segundo Farias e Rosenvald, a adoção "trata-se de mecanismo de determinação de uma relação jurídica filiatória, através do critério socioafetivo, fundamentado no afeto, na ética e na dignidade das pessoas envolvidas", onde determinada pessoa será inserida em uma família substituta, sempre levando em consideração o melhor interesse do infante, bem como sua proteção integral, tendo sempre a participação e o consentimento do Poder Judiciário (FARIAS; ROSENVALD, 2014, p. 934).

Na legislação brasileira, está estabelecido ser de suma importância que se preserve o interesse do adotado, conforme disciplina o art. 43 do ECA, sendo expresso pelo texto normativo, que somente poderá deferir-se a adoção quando apresentar-se-á reais vantagens para o adotado, tendo o filho adotivo todos os direitos dos filhos naturais, conforme o art. 41 do ECA (BRASIL, 1990).

Ainda, antes de realizar-se o instituto da adoção, ocorre a chamada destituição do poder familiar e, somente após passar por esse procedimento, é que uma criança ou adolescente poderá ser adotado por uma família.

Quando há descumprimento aos direitos das crianças e dos adolescentes, abre-se um procedimento de suspensão ou perda do poder familiar, dependendo do caso específico. No ECA encontram-se as regras processuais quando é proposta uma ação de suspensão ou perda do poder familiar, vindo, subsidiariamente, a ser aplicado as normas do Código de Processo Civil.

A suspensão do poder familiar trata-se de restrição quanto ao exercício de função de pais, o qual sempre será estabelecido através de decisão judicial, podendo perdurar até quando 
for necessário, sempre atendendo aos interesses da criança e do adolescente. $\mathrm{O}$ art. 1637 do Código Civil (BRASIL, 2002) define a respeito da possibilidade de suspensão do poder familiar.

No momento em que cessar a causa que motivou a suspensão, os pais voltam a exercer o poder familiar. A lei não estabelece tempo máximo ou mínimo para durar a suspensão, ela perdurará até que for necessário e existir perigo com relação à criança ou adolescente. (GONÇALVES, 2010, p. 416).

A destituição do poder familiar, por sua vez, demonstra-se cabível quando o pai ou a mãe castigar de forma imoderada o (s) filho (s), deixa-lo em abandono ou praticar atos contrários à moral e aos bons costumes. Se, ao final, a ação de destituição do poder familiar for julgada procedente, a criança ou adolescente será colocado em família substituta, na modalidade de guarda, tutela ou adoção (SCHREIBER; MANGUEIRA, 2014, p. 188).

A seguir serão analisados os principais requisitos para que aconteça um processo de adoção, já que, sem que esses requisitos sejam observados e criteriosamente seguidos, uma pessoa não poderá adotar uma criança ou adolescente.

Comumente, podem adotar todas as pessoas civilmente capazes, com idade superior a 18 anos, independentemente de seu estado civil. Toda e qualquer pessoa tem o direito à convivência familiar, podendo, de maneira eventual, ocorrer através do instituto da adoção, ou seja, qualquer pessoa, seja ela solteira, viúva, divorciada, casada ou unida estavelmente terá a oportunidade de adotar, se assim o quiser desde que revele adequadas condições para a inclusão do adotando em núcleo familiar substituto (FARIAS; ROSENVALD, 2014, p. 940).

Ainda, complementam os autores (FARIAS; ROSENVALD, 2014, p. 940), que igualmente, não pode ser cogitada, sequer de modo remoto, quanto a alguma interferência do processo de adoção por causa da orientação sexual do adotante. Não é a sua orientação sexual que irá definir a possibilidade da medida, mas a sua conduta, o seu comportamento que será levado em conta, a fim de verificar o interesse do adotando.

Dentre os requisitos exigidos pelo ECA para a adoção, destacam-se, principalmente: a) idade mínima de 18 anos para o adotante (ECA, art. 42, caput); b) diferença de 16 anos entre o adotante e o adotado (art. 42, $\S 3^{\circ}$ ); c) consentimento dos pais ou dos responsáveis legais de quem se deseja adotar; d) concordância deste, se contar com mais de 12 anos de idade (art. 28, $\S 2^{\circ}$ ); e) processo judicial (art. 47, caput) e, f) efetivo benefício para o adotando (art. 43) (BRASIL, 2009). 
A inviabilidade da manutenção na família natural ou extensa, as vantagens para o adotado e legitimidade dos motivos do adotante, o consentimento dos pais do adotando e, sendo adolescente, também o dele, a sentença deferindo a adoção, proferida em processo judicial, após o estágio obrigatório de convivência do requerente e da criança e do adolescente e, por último, a capacidade e legitimidade do adotante, são, resumidamente, as fases que um processo de adoção necessariamente precisa passar (COELHO, 2016, s/p).

Ninguém poderá ser adotado por duas pessoas, salvo se estas forem casadas (aqui cabendo as pessoas em união estável), separadas, divorciadas ou conviventes. Exceto as pessoas casadas e que vivem em união estável, a adoção ocorrerá, mas somente se concordarem conjuntamente com o ato de adotar, estando elas sob a guarda e regime de visitas, e desde que o estágio de convivência tenha sido iniciado na constância da sociedade conjuga, regras essas todas elencada no ECA. Vale ressaltar quanto a possibilidade de adoção por casal homoafetivo, assunto esse pacificado pela doutrina e jurisprudência (WALD; FONSECA, 2009, p. 323).

A Constituição Federal, em seu art. 227, $\S 5^{\circ}$, determina que a adoção seja assistida pelo Poder Público, exatamente para que seja atendido o requisito fundamental da adoção, de trazer vantagens para o adotado (BRASIL, 1988).

Segundo esse preceito constitucional, é atribuída, ao Poder Judiciário, a competência para cuidar do instituto da adoção. Para desincumbir-se adequadamente de suas funções, o Poder Judiciário deve organizar, em cada comarca ou foro regional, o cadastro das crianças e adolescentes em condições de serem adotadas e o de pessoas interessadas em adotar. A inscrição nesses cadastros depende de prévia consulta aos órgãos técnicos do Juizado da Infância e da Juventude e ao Ministério Público (COELHO, 2016, s.p).

Existem algumas restrições à adoção no sistema jurídico brasileiro, já que não podem adotar os ascendentes, descendentes e irmãos, por exemplo, os avós não podem adotar os netos, como prevê o art. 42 do ECA (BRASIL, 1990).Também, não poderá o tutor ou curador adotar o tutelado ou curatelado enquanto não prestar contas de sua administração (BRASIL, 1990).

A adoção é um ato personalíssimo, portanto, somente poderá ser promovida pessoalmente pelo adotante, sendo vedada a adoção por meio de procuração, conforme disciplina o art. 39, $\$ 2^{\circ}$ do ECA (BRASIL, 1990). 
Tendo em vista que na legislação brasileira é necessário que exista o consentimento dos pais ou responsáveis legais do adotando, muitos dos processos de adoção poderão estar cumulados com a destituição do poder familiar (FARIAS; ROSENVALD, 2014, p. 959).

Nas lições de Granato (2010, p. 102), o processo de adoção será de jurisdição voluntária quando tiver o consentimento dos pais biológicos ou estes já tiverem sido destituídos do poder familiar. E o processo será contencioso quando os pais biológicos ainda estiverem no exercício do poder familiar e não autorizarem de maneira expressa a ação de adoção. Quando o processo for contencioso, os autos seguem o rito ordinário do Código de Processo Civil.

A competência para processar e julgar as ações de adoção é do Juiz da Infância e Juventude ou, então, de um juiz que exerça essa função, nos termos do art. 148, III, do ECA (BRASIL, 1990).O processo de adoção irá ocorrer em segredo de justiça, nos termos do art. 206 do ECA, bem como é isento de custas e emolumentos, conforme art. 141, § $2^{\circ}$, do ECA. A grande importância que deve ser enfatizada é que o processo de adoção é gratuito, muitas vezes esse aspecto é desconhecido do público em geral. Outrossim, através do art. 147, do ECA, define que a competência será determinada pelo domicílio dos pais ou responsável, ou no lugar em que se encontrar o infante, na falta destes (BRASIL, 1990).

Durante o processo o juiz vai verificar se a adoção contempla o real benefício do adotando, apresentando vantagens. O juiz sempre irá apreciar os elementos de prova, a fim de garantir que esse efetivo benefício não se apresenta, apenas, pela ótica objetiva, mas pelo prisma subjetivo. Durante a instrução processual, o juiz deve designar data e horário para ouvir, pessoalmente, o adotante, o adotando e, quando possível, os pais biológicos da criança e do adolescente (FARIAS; ROSENVALD, 2014, p. 960).

Não pode-se deixar esquecer a necessidade de realização do estudo psicossocial do caso, conforme prevê o artigo 167, do ECA, sendo dispensável nas ações que envolvam adoção de adultos (BRASIL, 1990).

Os candidatos que optarem pela adoção, deverão apresentar na petição inicial do processo de habilitação uma série de documentos, dentre eles destacam-se: comprovantes de renda e residência, atestado de sanidade mental e física, certidão de antecedentes criminais e negativa de distribuição cível (art. 197-A, do ECA). Os candidatos deverão indicar o perfil que aceitam adotar da criança ou adolescente. Outrossim, o Ministério Público pode requerer a designação de audiência para a oitiva dos postulantes e de eventuais testemunhas (art. 197B, II, do ECA) (BRASIL, 1990). 
Ao ser deferida a habilitação, o postulante é inscrito no cadastro nacional de adoção, conforme art. 50 do ECA, cuja ordem cronológica deverá ser observada, conforme art. 197-E, $\S 1^{\circ}$, do ECA (BRASIL, 1990).A adoção é irrevogável. Uma vez estabelecida a adoção, a sentença que a pronunciou somente poderá ser rescindida de acordo com os princípios processuais. Até mesmo a morte dos adotantes ou do adotado não restabelecerá o vínculo originário com os pais biológicos (VENOSA, 2009, p. 292).

Ao ser deferida, a sentença de adoção é averbada, mediante mandado judicial, no registro civil, sem qualquer referência à origem do ato. A natureza do vínculo não poderá ser revelada no registro de nascimento do adotado, bem como não poderá conter nenhuma observação do ato (DIAS, 2011, p. 506).A procedência do pedido de adoção, naturalmente, implica na mudança do sobrenome do adotado que, a toda evidência, passará a ter os nomes patronímicos do adotante ((FARIAS E ROSENVALD, 2014, p. 955).

Há requisitos bem específicos para que uma pessoa possa adotar uma criança ou adolescente, bem como o processo de adoção muitas vezes pode se demonstrar, de certa forma, desgastante para as pessoas envolvidas, pois muitas vezes um processo de adoção está acompanhado pela perda do poder familiar, característica principal para que a adoção ocorra.

A seguir, tendo em vista o mencionado acima, traz-se o estudo realizado sobre dois princípios fundamentais básicos para o Direto, os quais são aplicáveis também ao Direito de Família e consequentemente aos processos de adoção, quais sejam os princípios do devido processo legal e a razoável duração do processo, os quais estabelecem critérios básicos a serem observados nos processos nos processos de adoção.

\section{O TEMPO DOS PROCESSOS: o devido processo legal e a razoável duração do processo}

A seguir será abordado o tempo de duração dos processos ou a duração razoável dos processos, bem como o devido processo legal. Abordar-se-á a questão com amparo na Constituição Federal e demais legislações, bem como com a ajuda de vários autores que abordam o tema, buscando-se construir base para a análise dos processos de adoção que será feita no próximo ponto.

Justifica-se o estudo realizado, eis que o tema é um dos mais criticados por aqueles que necessitam recorrer à justiça para a resolução de conflitos. E ao adentrar o tema nos processos de adoção, vem a tomar ainda mais importância, devido ao fato de que são 
processos que carregam uma grande carga emocional, e com o passar do tempo vem a desgastar psicologicamente e emocionalmente os envolvidos, e, neste sentido, o tempo de duração dos processos possui ainda mais importância.

A duração razoável do processo, bem como o devido processo legal, temas os quais serão abordados de maneira incansável, tratam-se de direitos fundamentais consagrados em diversos documentos internacionais de proteção e de promoção dos direitos humanos.

Quanto aos direitos fundamentais, estes integram a essência do Estado constitucional ao lado da definição da forma de Estado, do sistema de governo e da organização do poder, constituindo, neste sentido, não apenas parte da Constituição formal, mas também elemento fundamental na Constituição material. Para além disso, estava definitivamente consagrada a íntima vinculação entre as ideias de Constituição, Estado de Direito e direito fundamentais. O Estado constitucional determinado pelos direitos fundamentais assumiu feições de Estado ideal, cuja concretização passou a ser tarefa permanente (SARLET, 2009, p. 58).

Tendo em vista que o Estado Democrático de Direito assumiu o trabalho de proclamar os direitos fundamentais, bem como declarou o dever de implantar e torná-los efetivos, o processo tomou para si o papel de se tornar a força instrumental para garantir todos os direitos ameaçados ou violados (THEODORO JÚNIOR, 2008, p. 6).

De acordo com Nicolitt (2014, s.p), o tempo no processo traz em questão a própria ideia de justiça, expressão que, por si só, é de difícil definição. Sabe-se que a justiça é vista das mais variáveis maneiras, seja ela tida no campo da sociologia, na filosofia e no próprio campo do direito. No entanto, há de ser utilizada a perspectiva aristotélica de justiça, a qual é vista como uma mediana, ou seja, "a justiça é uma virtude e se traduz em uma mediana, a justa medida".

Nesse sentido, visto que a busca por um processo célere é a primazia no direito atual, importante referir que este direito fundamental apresenta-se juntamente com o princípio constitucional do devido processo legal. Para a solução de litígios é necessário seguir ditames específicos, os quais estão definidos na norma legal, como, por exemplo, para a propositura de um processo de adoção, a criança ou adolescente deverá ter sido destituída de sua família biológica, o qual somente será possível realizar-se através de um devido processo legal.

\subsection{O Devido Processo Legal}


Considerado um princípio fundamental, base para todos os demais princípios, o devido processo legal garante aos litigantes o direito a um processo e a uma sentença justa.Faz algum tempo que o instituto do devido processo legal é encontrado no centro do sistema processual. O devido processo pode ser definido como sendo a própria essência do sistema processual, já que, ao buscar-se um processo legítimo e justo já estará se falando em devido processo legal. Por dado motivo, que qualquer irregularidade viola o princípio do devido processo legal (RAMOS, 2007, p. 101).

A primeira vez que usou-se a expressão do devido processo legal (due processo of the law), foi em 1354, pelo Rei Eduardo III, na Inglaterra, quando o soberano confirmou as Leis da Terra, dentre elas a Magna Carta da Liberdade. O texto de Eduardo III discorre que nenhum homem de qualquer estado ou condição que ele esteja, possa ser posto fora da terra ou da posse, ou molestado, ou aprisionado, ou deserdado, ou condenado à morte sem antes ser levado a responder um devido processo legal (RAMOS, 2007, p. 103).

Em 1988, a Constituição consagrou o due process of law, com a expressão de que ninguém será privado da liberdade ou de seus bens sem o devido processo legal (NICOLITT, 2014, s.p).Pacífico, portanto, que o inciso LIV do art. $5^{\circ}$ da $\mathrm{CF} / 88$, em sede doutrinária e jurisprudencial, prevê o direito fundamental ao devido processo legal (ALVES E SILVA, 2016, p. 01).

Além disso, a art. XI, $n^{\circ}$. 1, da Declaração Universal dos Direitos Humanos salienta que todo homem que for acusado de cometer um delito possui por direito ser presumido inocente até que seja provada sua culpabilidade de acordo com a norma legal, através de julgamento público, sendo sempre garantida a ampla defesa (MORAES, 2011, p. 297).

O fundamento constitucional do devido processo legal encontra-se nos artigos $5^{\circ}$, XXXV, LIV e LV, e 37 da Constituição Federal de 1988. Estabelece seu ideal, em sua dimensão principiológica, de protetividade dos direitos em todos procedimentos ou processos instituídos pelo Poder Público, bem como, o instituto do devido processo legal exige uma interpretação racional das regras e dos princípios procedimentais (GROSS, 2014, p. 4).

Salienta Portanova (2005, p. 145), a necessidade de o processo obedecer às normas previamente estipuladas em lei, como forma de garantia do cidadão, tanto ao exercício de acesso ao Poder Judiciário quanto ao desenvolvimento processual de acordo com as normas previamente estabelecidas.

Para Bueno (2012, p. 143), o princípio do devido processo legal deve ser compreendido como sendo o princípio regente da atuação do Estado-juiz. Explica, ainda, que 
o processo é devido pois em um Estado Democrático de Direito, não basta a atuação do Estado de qualquer forma, mas sim, que a atuação deste, seja de forma bem específica com cada caso, de acordo com as regras preestabelecidas e assegurem, amplamente, a participação daqueles que procuraram o Poder Judiciário para a solução de seus litígios.

Dessa forma, pelo princípio do devido processo legal, a Constituição garante a todos que a solução dos conflitos obedecerá aos mecanismos jurídicos de acesso e desenvolvimento do processo, previamente estabelecido em leis (PORTANOVA, 2005, p. 145).

No direito pátrio, anseia-se pela prevalência da celeridade processual, sempre buscando os meios de aplicação da justiça, com utilização dos meios recursais e garantindo o acesso à justiça, sem, contudo, procrastinar a solução dos conflitos. O processo deve ser célere, no sentido de que tramitações que perduram por anos para determinados casos não podem ser admitidas porquanto serão injustas, pois não alcançaram o primordial desígnio da tutela jurisdicional, de justapor o poder-dever do estado de declarar e realizar o direito.

Neste sentido vale mencionar que nenhuma criança ou adolescente será retirado de sua família natural arbitrariamente, mas com direito ao processo legal de sua família biológica, ao qual é dado todas as prerrogativas para demonstrar se possui ou não condições de manter a criança ou adolescente sob seus cuidados, bem como estabelece a lei um prazo razoável para cumprir com todas as fases processuais, tanto nos processos de destituição do poder familiar, quanto nos processos de adoção.

\subsection{A Razoável Duração do Processo}

O processo deve ter andamento o mais célere possível, contudo, nem sempre é o que efetivamente ocorre, pois muitas vezes encontram-se vários entraves, entre estes pode-se citar o acúmulo de serviço e o pequeno número de juízes e serventuários.

O devido processo legal tem sua origem com a Magna Carta de 1215, assim como o princípio da duração razoável do processo. Em seu art. 40, afirmava-se que o Estado não poderia protelar o direito à obtenção de justiça, ou seja, a garantir um processo sem atrasos indevidos (SANTOS, 2014, p. 4).

A Emenda $n^{\circ} 45 / 2004$ colocou à celeridade processual a condição de princípio constitucional, ao incorporar à Lei Magna, no elenco das garantias fundamentais, em seu art. $5^{\circ}$, o inciso LXXVIII (MEDINA, 2012, p. 58). Incluído agora, também, no artigo $4^{\circ}$ no Novo Código de Processo Civil. 
Salienta Theodoro Júnior (2008. p. 10), que a garantia de duração razoável do processo já era consagrada como garantia fundamental pela Constituição de 1988. Com efeito, por força do $\S 2^{\circ}$ de seu art. $5^{\circ}$, os direitos e garantias fundamentais não são apenas os expressos nos diversos incisos daquela declaração, mas incluem, também, “outros decorrentes do regime e dos princípios por ela adotados, ou dos tratados internacionais em que a República Federativa do Brasil seja parte".

Ao ser classificado como direito fundamental, a razoável duração do processo, de acordo com o constituinte, possui como objetivo poder dar novas perspectivas para a defesa dos direitos dos cidadãos brasileiros, na área judicial e administrativa, com o fim de garantir direitos mais eficazes, com maior segurança, diante do surgimento de novas medidas e decisões (BORGES, 2012, p. 70).

De acordo com Faria, o mundo globalizado exige que as pessoas se dediquem muito mais que seus pais no passado. Sempre há a grande e importante necessidade de estar atualizados, bem como, a importância do acesso à informação, fazendo com que o cidadão venha a se dedicar de forma integral em todas as tarefas do dia-a-dia, sejam elas pessoais, profissionais ou vitais (FARIA, 2010, p. 476).

Existe, atualmente, uma grande e crescente preocupação com relação ao tempo de duração dos processos. De acordo com Cruvinel e Faleiros (2010, p. 7718), "busca-se, nesse sentido, definir em qual momento o Estado-Juiz deveria oferecer o provimento final aos litigantes".

Segundo Nicolitt (2014, s.p), “o dever legal de se fixar por lei o prazo de duração razoável da relação jurídica deriva da própria natureza do estado Democrático de Direito", ou seja, somente quando os representantes do povo se manifestarem é que se estará dando integral cumprimento ao estabelecido no diploma de direitos humanos, em obediência aos princípios da legalidade e do devido processo legal.

Existe um apelo muito forte para que se encontre uma solução na lentidão do Judiciário Brasileiro. E não se pode falar em acesso a uma ordem jurídica e justa se o demandante de uma ação for submetido a uma infinita e indeterminada espera pela solução do litígio que o envolve. Ocorre que, por muitas vezes, esta demora não ocorre somente devido à estrutura dos procedimentos existentes. Muitas vezes essa morosidade se dá pela própria inércia e ineficiência da chamada máquina judiciária no momento em que os atos processuais são realizados, no cumprimento dos prazos e no grande número de serviço acumulado dentro 
das repartições públicas, além do déficit de servidores (CRUVINEL; FALEIROS, 2010, p. 7718).

É necessário buscar um julgamento mais célere, mais ágil, reconhecendo-se os meios necessários para a obtenção desta finalidade, mas não de forma generalizada, que venha a colocar em risco o ideal de segurança jurídica (BUENO, 2012, p. 186).

Nesse sentido, acrescenta Neves (2013, p. 80), que a celeridade processual nem sempre se torna possível, como, também, nem sempre é benéfica para a qualidade da prestação jurisdicional. Menciona ainda que o legislador não pode violar direitos fundamentais das partes somente com o fito de obter celeridade processual, sob pena de estar diante de situações ilegais e, de certa forma, injustas. Necessário compreender que demandas mais complexas exigem mais empenho e dedicação dos advogados e, sobretudo, dos juízes, por dado motivo, essas ações tendem a ser, naturalmente, mais demoradas, sem que com isso seja classificado como ofensa ao princípio constitucional.

$\mathrm{Na}$ busca para dar ao processo um curto prazo entre seu início até seu fim, a Lei $\mathrm{n}^{\circ}$. 11.419, de 19 de dezembro de 2006, regulamenta quanto a informatização do processo judicial, os chamados autos virtuais, o qual estabelece a possibilidade de utilização dos meios eletrônicos na tramitação de processos judiciais, bem como para a comunicação dos atos e transmissão das peças processuais, vindo a ocorrer com os processos cíveis, penal e trabalhista, bem como aos juizados especiais, em qualquer grau de jurisdição (MORAES, 2011. p. 354).

Quando se fala em tempo dos processos não há necessariamente que falar-se sobre a velocidade no tramite processual, tendo em vista que sua razoabilidade será ditada pela complexidade, ou não, do feito, portanto. Não há uma fórmula perfeita, pronta, a fim de que compreenda-se o tempo do processo, "a razoabilidade encontra, nesse aspecto, íntima relação com a efetividade do direito pleiteado, devendo a prestação jurisdicional atender a tal item sob pena de tornar o processo, como um todo, injusto" (MIGLIAVACCA; SOVERAL, 2015, p. $05)$.

Nessa linha adentra-se para os processos de adoção, visto que, na grande maioria das vezes aqueles que decidem entrar com o pedido de adoção devem iniciar um longo processo. Entre reunir documentos, comprovar aptidão, estabilidade psicológica e financeira e entrar na longa lista de espera, podem passar anos.

Entretanto, a felicidade da paternidade e a possibilidade de proporcionar um lar afetivo e seguro para que uma criança possa crescer e se desenvolver plenamente é razão 
suficiente para todos aqueles que decidem abrir suas vidas para uma criança ou um adolescente, vítimas de grande sofrimento em um momento tão prematuro de suas vidas.

Analisar-se-ão, na sequência, aspectos diretamente relacionados às motivações temporais dos processos de adoção, relacionando-se com o já exposto, notadamente, com o próprio processo de adoção e o cumprimento dos princípios do devido processo legal e da razoável duração do processo.

\section{MOTIVAÇÕES TEMPORAIS DOS PROCESSOS DE ADOÇÃO}

Muito debate-se nos dias atuais sobre a questão do tempo que um processo leva no Poder Judiciário Brasileiro. Ao tratar sobre o tema surgem inúmeras críticas, tendo em vista o conhecimento de que um processo pode levar vários anos para ter dirimido seu conflito.

Mesmo estando disciplinado no rol dos direitos fundamentais, elencados na Constituição Federal de 1988, o princípio da duração razoável do processo, por muitas vezes, não é efetivado por uma série de motivos, tais como excesso de trabalho, número reduzido de servidores, entre tantos outros.

A seguir abordar-se-á a questão quanto ao tempo de duração dos processos de adoção apresentando-se estudos acerca dos dados constantes no Cadastro Nacional de Adoção e, ao mesmo tempo em que serão apresentados os dados levantados, ao final busca-se tentar sugerir possíveis soluções para tornar o tempo dos processos de adoção o melhor e menor possível, sempre considerando o melhor interesse da criança ou adolescente envolvido, principalmente quando a questão trata de casos urgentes, onde envolvam crianças e adolescentes em situação de risco.

\subsection{Motivações Temporais dos Processos de Adoção}

O processo de Adoção tem apresentado ser lento no Brasil, apesar das alterações que sofreu ao longo do tempo. Isso acaba por desmotivar os candidatos à adoção que possuem o desejo de formar uma família com filhos, comprometendo igualmente, e de forma demasiada, a estrutura das crianças e adolescentes sujeitados a aguardar em uma "fila de espera" dos cadastros de adoção, que não parece diminuir.

Em 03 de agosto de 2009 foi promulgada a Lei Nacional da Adoção, Lei nº 12.010/2009. Quando sancionada possuía como principal objetivo tornar mais célere os Revista Juris Poiesis - Rio de Janeiro. Vol.21-n²5, 2018, pg.91-120. ISSN 2448-0517 
processos de adoção, com o fim de reduzir o tempo de permanência das crianças e/ou adolescentes nos abrigos, bem como objetivava priorizar a permanência da criança ou adolescente em sua família de origem e por fim unificar o cadastro de adoção (GONÇALVES, 2009, p. 09).

Segundo informações contidas na página virtual do Conselho Nacional de Justiça, a burocraciaainda é o principal entrave para o processo de adoção no Brasil, tendo em vista que o excesso de regras, divisões e as práticas processuais que são supérfluas, apenas atrasam o funcionamento de todo o sistema. Ao passo que essa morosidade ainda ocorre sobre os processos de adoção, surgem os chamados "filhos de abrigo", ou seja, crianças que acabam passando sua infância e adolescência nas unidades de acolhimento, até que atingiam a maioridade (CNJ, 2015, s.p).

Quanto aos chamados "filhos do abrigo" merece destaque o que referem Bragança e Pereira Junior (2015, p. 95):

\begin{abstract}
Dois anos é o prazo máximo estipulado para que as crianças fiquem em abrigos, mas a realidade no Brasil é discrepante, como se pôde observar com este estudo. Muitos indivíduos ficam até completar a maioridade, e quanto mais o tempo vai passando sem que eles sejam adotados enquanto crianças, menores as chances de isso acontecer com o passar do tempo. Crianças que possuem irmãos, doença de algum tipo, ou mesmo histórico familiar que vá contra as idealizações dos pais que aguardam para adotar, acabam ficando para trás - o que contribui para o aumento no tempo de espera no processo de adoção.
\end{abstract}

O termo abrigar é definido pelo Estatuto da Criança e do Adolescente como sendo uma medida de proteção, no entanto, esta medida somente será aplicada quando a convivência familiar apresentar riscos para a criança e adolescente (GONÇALVES, 2009, p. 20).

O fato de estar acolhida em uma instituição não retira qualquer direito da criança ou adolescente, que continuam sendo sujeitos de direitos. Santos (2016) refere:

\footnotetext{
Atualmente, a criança ou adolescente, quando acolhido numa instituição de abrigo deve continuar a frequentar a escola, espaços de lazer, cultura e esporte, entre outros. Sempre que possível será realizada a reaproximação do acolhido com sua família de origem, a família extensa, entre outros, promovendo- se também o elo de fortalecimento a criança ou adolescente e a comunidade.
}

De acordo com as informações do Conselho Nacional de Justiça, sinalizou-se que os processos de habilitação para a adoção ocorrem em menor tempo nas regiões Nordeste e Sudeste do Brasil, enquanto os processos de habilitação para a adoção das regiões Centro- 
Oeste e Sul são os que possuem maior tempo desde sua propositura até o trânsito em julgado, atingindo tempos médios maiores de dois anos (CNJ, 2015, s.p).

Ressalta-se que antes que ocorra o processo de adoção, é necessário que venha a ocorrer o processo de destituição do poder familiar. Segundo Digiácomo (2013, s.p), o grande culpado pela demora na destituição do poder familiar é porque ocorre o descumprimento da Lei. Eis que está previsto na Lei de Adoção o prazo de 120 diaspara cumprir os procedimentos, bem como o artigo 152, em seu parágrafo único, do Estatuto da Criança e do Adolescente, o qual foi alterado pela da Lei Nacional de Adoção, garante a prioridade absoluta na tramitação dos processos desta natureza (BRASIL, 1990).

Ressalta, ainda, que o atraso nos processos de adoção se dá, de modo geral, pelo fato de que os adotantes fazem muitas exigências com relação ao perfil do futuro adotado. Segundo ele, se uma pessoa aceitar uma criança mais velha o processo se torna mais rápido. No entanto frisa, ainda, que é importante agir com rapidez, mas sempre tomar cuidado para que não ocorra nenhuma precipitação, a fim de não correr o risco de cometer alguma injustiça (DIGIÁCOMO, 2013, s.p).

Quando ocorre o acolhimento da criança ou do adolescente e não há possibilidade de reinserção na família de origem é procedido com o processo de destituição familiar, que, por fatores como a simples dificuldade de citar os genitores, pode demorar e, com isso, a criança passar anos no acolhimento institucional, o que agrava a possibilidade de ser adotada.

Além disso, traz-se novamente Gonçalves (2009, p. 20), pois refere que ao decidir pela adoção, a grande maioria das pessoas idealiza uma criança, recém-nascida, geralmente branca, de olhos azuis, enfim, idealizam uma criança perfeita. No entanto, no momento em que visitam as casas de acolhimento percebem que a realidade é outra, e por dado motivo, acabam gerando um sentimento de frustração, tendo em vista que lá somente encontrarão crianças e adolescentes normais, com um histórico de vida já bem complicado, pela curta idade de vida que possuem.

Dados atuais apresentados pelo CNJ demonstram que cerca de 14,3\% dos pretendentes à adoção aceitavam crianças com até 5 anos de idade. Importante frisar que atualmente o total de pretendentes cadastrados para a adoção é de 42.831 pessoas, isso equivale aos $100 \%$ de pessoas cadastradas no CNA. Quando analisa-se o dado de $14.3 \%$ de 
pretendentes à adoção aceitavam crianças com até 5 anos de idade, quer dizer que desse total de pretendentes apenas 6.124 aceitam adotar crianças com esta faixa etária ${ }^{3}$.

É importante compreender a idade das crianças quando são disponibilizadas no CNA, bem como o efeito que os processos judiciais relacionados à adoção têm sobre essa idade, incluídos aqui, também, os processos de guarda, destituição do poder familiar, medidas protetivas e adoção, pois se faz necessário entender como essa realidade pode ser mudada. Nesse ponto, encontram-se dois problemas. Um se refere quando as crianças e adolescentes entram no sistema tardiamente; já o outro se refere aos casos nos quais as crianças entram antes dos 5 anos no sistema, mas ficam retidas devido aos entraves processuais (NUNES, 2015, p. 25).

Ainda sob o mesmo raciocínio, refere que quanto ao primeiro caso, este não tem nenhuma relação direta com o tempo dos processos, já o segundo caso, o tempo dos processos é critério fundamental, eis que o lapso de tempo que ocorre entre a entrada da criança no sistema de adoção e sua disponibilização, propriamente dita, para a adoção é que vai determinar as chances em ser colocada em uma nova família, pois quando esse lapso de tempo é muito longo, a criança pode ultrapassar a barreira dos 5 anos de idade e devido a isso, ver suas chances de ser adotada serem reduzidas a valores baixos (NUNES, 2015, p. 25).

Abaixo estão relacionados alguns dados em números quanto às crianças $\mathrm{e}$ adolescentes disponíveis para a adoção e dados dos pretendentes, dados estes retirados da página virtual do Conselho Nacional de Justiça ${ }^{4}$.

$\begin{array}{lll}\text { Total de pretendentes cadastrados: } \quad 42.831 & \mathbf{1 0 0 , 0 0 \%}\end{array}$

Total de pretendentes que aceitam 20.198
todas as raças:
$\begin{aligned} & \text { Total de pretendentes que são } \\ & \text { indiferentes em relação ao sexo da } 27.320\end{aligned}$
criança:

\begin{tabular}{llll|} 
Total de pretendentes que não & & $\mathbf{6 4 . 9 4 \%}$ \\
aceitam adotar irmãos: & & 27.816 & \\
\hline $\begin{array}{l}\text { Total de pretendentes que são da } \\
\text { Região Norte }\end{array}$ & $\mathbf{1 . 5 2 5}$ & $\mathbf{1 0 0 \%}$ \\
\hline
\end{tabular}

3 Referidos dados foram retirados do Cadastro Nacional de Adoção. Disponível em: < http://www.cnj.jus.br/cnanovo/pages/publico/index.jsf>. Acesso em 30 jan. 2018.

$\begin{array}{llllll}4 & \text { Conselho Nacional de Justiça } & - & \text { CNJ. } & \text { Disponível } & \text { em: } \\ \text { http://www.cnj.jus.br/cnanovo/pages/publico/index.jsf }>, & & & \text { e } & \end{array}$ http://www.cnj.jus.br/cnanovo/pages/publico/index.jsf>. Acesso em 30 jan. 2018. 


\begin{tabular}{|c|c|c|}
\hline $\begin{array}{l}\text { Total de pretendentes que são da } \\
\text { Região Nordeste }\end{array}$ & 5.346 & $100 \%$ \\
\hline $\begin{array}{l}\text { Total de pretendentes que são da } \\
\text { Região Centro-Oeste }\end{array}$ & 3.228 & $100 \%$ \\
\hline $\begin{array}{l}\text { Total de pretendentes que são da } \\
\text { Região Sudeste }\end{array}$ & 20.058 & $100 \%$ \\
\hline $\begin{array}{l}\text { Total de pretendentes que são da } \\
\text { Região Sul }\end{array}$ & 12.674 & $100 \%$ \\
\hline $\begin{array}{l}\text { Total de pretendentes que aceitam } \\
\text { crianças com até } 1 \text { anos de idade: }\end{array}$ & 5.867 & $13.7 \%$ \\
\hline $\begin{array}{l}\text { Total de pretendentes que aceitam } \\
\text { crianças com até } 17 \text { anos de idade: }\end{array}$ & 49 & $0.11 \%$ \\
\hline
\end{tabular}

Verifica-se, pela análise da tabela acima, que o número de pretendentes a adotar é bastante razoável, sendo que todas as pessoas que estão inseridas no cadastro já passaram por um processo de habilitação e estão aguardando serem chamadas a adotar.

É importante destacar, ainda, que os dados apresentados na tabela acima são apontados por estudiosos e pesquisadores da área como os principais fatores pelo tempo de aguardo na fila da adoção, ou seja, pretendentes que não aceitam adotar irmãos e que desejam adotar crianças recém-nascidas ou até um ano de idade, o que confronta com os dados disponíveis na próxima tabela, referente às crianças e adolescentes que estão disponíveis para serem adotados.

Total de crianças/adolescentes cadastradas: $\quad \mathbf{8 . 4 3 0}$ $100,00 \%$

\begin{tabular}{|c|c|c|}
\hline Total que possuem irmãos: & 4.984 & $59.12 \%$ \\
\hline $\begin{array}{l}\text { Total de crianças/adolescentes } \\
\text { que possuem problemas de } \\
\text { saúde: }\end{array}$ & 2.155 & $25.56 \%$ \\
\hline $\begin{array}{l}\text { Total de crianças/adolescentes } \\
\text { que são da Região Norte: }\end{array}$ & 367 & $100 \%$ \\
\hline $\begin{array}{l}\text { Total de crianças/adolescentes } \\
\text { que são da Região Nordeste: }\end{array}$ & 1.147 & $100 \%$ \\
\hline $\begin{array}{l}\text { Total de crianças/adolescentes } \\
\text { que são da Região Centro-Oeste: }\end{array}$ & 736 & $100 \%$ \\
\hline Total de crianças/adolescentes & 3.608 & $100 \%$ \\
\hline
\end{tabular}


que são da Região Sudeste:

$\begin{array}{lll}\text { Total de crianças/adolescentes } & 2.572 & 100 \% \\ \text { que são da Região Sul: } & & \\ \begin{array}{l}\text { Total de crianças com menos de } \\ \text { um ano }\end{array} & 285 & 3.38 \% \\ \text { Total de crianças com } 17 \text { anos } & 617 & 7.32 \%\end{array}$

Tabela 2: Dados das crianças disponíveis para a adoção registradas no Cadastro Nacional de Adoção (adaptada).

Nas palavras de Kreuz (2013, s.p), a questão do prazo é um dos grandes dilemas da Justiça da Infância e Juventude. Ao decidir uma questão com muita rapidez, há a probabilidade de estar impedindo que a criança ou adolescente seja reinserida no seio da família biológica. No entanto, ao demorar a decidir, há a probabilidade de estar inviabilizando uma futura adoção.

Segundo a Lei de Adoção o juiz deve esgotar todos os meios possíveis e necessários para reintegrar a criança ou adolescente na família natural ou extensiva. Sob esta perspectiva, Kreuz indagou por quanto tempo se deve tentar a reintegração, complementando, ainda que todo esse processo é uma questão de difícil avaliação (KREUZ, 2013, s.p).

Ainda nas palavras de Kreuz (2013, s.p), inúmeras vezes é perdido um tempo inestimável na busca pela reintegração das crianças e adolescentes em suas famílias biológicas. Para diminuir esse tempo se faz necessária a existência de equipes interdisciplinares. A destituição do poder familiar não pode ocorrer de maneira arbitrária.

Observa-se ainda que os pais biológicos possuem direito à defesa, produção de provas, bem como de recursos, os quais muitas vezes demoram anos até serem julgados. E enquanto se passam anos até que se tenha uma decisão final, as crianças crescem nas unidades de acolhimentos. Os processos judiciais são imprescindíveis, no entanto não podem demorar anos sem que haja uma solução. Vale lembrar que a lei determina que os recursos sejam julgados no prazo máximo de 60 dias, o que, por muitas vezes, não é observado (KREUZ, 2013, s.p).

Essa demora gera muitas consequências para as crianças acolhidas, bem como para os adotantes envolvidos, gerando um sofrimento psicológico para ambos devido à demora do processo, podendo gerar a desmotivação dos candidatos à adoção, devido a essa morosidade, vindo a ocasionar uma diminuição na vontade de adotar ou até mesmo a própria desistência da adoção (BRAGANÇA; PEREIRA JUNIOR, 2015, p. 92). 
Quanto ao acolhimento institucional, nota-se que se direciona fortemente para crianças com mais idade ou adolescentes, ou seja, quanto maior a idade da criança acolhida e aguardando pela adoção, menores são as suas chances de serem adotadas. Souza (2012, p. 53) refere que "A motivação real é um dos fatores para o sucesso. Além disso é necessária a disponibilidade para receber, compreender e atender uma criança crescida, com vontade própria e aceitá-la como é”.

Não apenas o tempo em que está acolhida deve ser respeitado, mas, principalmente, todos os traumas ocorridos anteriormente ao acolhimento, rejeições da família biológica e dificuldades inerentes à idade.

O longo processo de adoção afronta o princípio da prioridade absoluta, no que tange aos casos que envolvam crianças e adolescentes, tendo em vista que os infantes passam por longas filas de espera, sem que haja qualquer amparo familiar que, como visto, é de suma importância para o crescimento saudável (SOUZA, 2016, p. 50).

Nesse passo, Souza (2016, p. 50) refere que se nota que há severas críticas por parte da doutrina brasileira quanto a morosidade dos processos de adoção, posto que uma vez estando em jogo o melhor interesse da criança ou do adolescente, tais procedimentos devem ser agilizados, suprimindo seu prolongamento desnecessário.

Outra questão relevante diz respeito a vulnerabilidade social de uma parcela carente da população, tida como causa primária do problema. Explica-se que muitas das crianças e adolescentes envolvidas no sistema de adoção advêm de famílias vulneráveis, desprovidas de apoio sócio educacional, bem como seus genitores, de certo modo, também são vítimas da falta de estrutura estatal (NUNES, 2015, p. 26).

Assim percebe-se, que mesmo com a antecipação de todos os direitos previstos na Constituição Federal de 1988, no Estatuto da Criança e do Adolescente e na Lei de Adoção 12.010/09, o direito ao convívio familiar, o maior benefício da criança e do adolescente, a proteção integral e a prioridade absoluta de seus direitos, o processo de adoção ainda vai de encontro com inúmeros entraves, especialmente a morosidade devido as obstruções existentes para a concretização da adoção.

Com isso, a seguir serão apresentados medidas que tem sido tomadas para que seja possível agilizar os processos de adoção, sempre resguardado os direitos de crianças e adolescentes envolvidos, analisando-se, especialmente, um projeto de lei que está em tramitação e a Lei n. 13.509/17. 


\subsection{Considerações sobre possíveis soluções ao tempo dos processos}

Estabelecem os arts. 152, parágrafo único do Estatuto da Criança e do Adolescente (ECA), 1048, inciso II, do Código de Processo Civil (CPC) e $2^{\circ}$, §2 $2^{\circ}$, do Provimento $\mathrm{n}^{\mathrm{o}}$ 36/2014 do Conselho Nacional de Justiça (CNJ, 2014) que, os processos de suspensão, destituição do poder familiar, adoção e demais procedimentos previstos no ECA, possuem prioridade absoluta na tramitação, sob pena de responsabilidade. Bem como estabelece o art. 163 do ECA que o prazo máximo para conclusão do procedimento da perda e da suspensão do poder familiar será de 120 dias.

Muitos são os fatores que influenciam os prazos processuais, tendo como alguns dos motivos para essa demora na realização dos procedimentos, desde a falta de serventuário, até a falta de legislação específica. Ocorre que quanto aos processos que têm tramitação preferencial, como é o caso dos processos de adoção, faz-se necessário encontrar uma solução que dê resultados e que esses resultados que sejam visíveis.

Quanto a esta questão, foi sancionada a Lei n. 13.509 de 22 de novembro de 2017, que visa encontrar soluções para a morosidade dos processos de adoção. Ainda está em tramitação o PL n ${ }^{\circ}$ 5443/2016, cuja autoria é do Deputado Carlos Bezerra e traz como primazia a autorização da adoção por parte de quem recebeu dos genitores, de forma expressa, criança ou adolescente para adoção, ou tenha acolhido criança em situação de risco em razão de abandono (BRASIL, 2016b).

A legislação em questão é oriunda do PL nº 5850/2016, de autoria do Deputado Augusto Coutinho, que se justifica quanto ao fim de agilizar os procedimentos relacionados à destituição do poder familiar e à adoção de crianças e adolescentes (BRASIL, 2016a).

Inicialmente deve-se realizar a análise do Projeto de Lei 5443/2016 por seu impacto ser mais restrito e posteriormente, à legislação aprovada recentemente.

É importante referir que o PL 5443/2016 traz como justificação para sua elaboração que, com a inclusão do art. 50-A no ECA, seriam autorizadas adoções independentemente da ordem de inscrição no Cadastro Nacional de Adoção (CNA), pois, segundo o Deputado Carlos Bezerra, a obediência da ordem de inscrição objetiva coibir adoções irregulares, em desconformidade com a norma, no entanto essa mesma obediência à ordem de inscrição pode impedir a realização de adoções em situações distintas, trazendo, dessa forma, prejuízos ao adotando (BRASIL, 2016b). 
Refere ainda o PL 5443/2016 quanto a outra situação distinta, ou seja, quanto a criança que fora abandonada e que fora encontrada e acolhida por uma família, que em nenhum momento havia cogitado a hipótese em adotar essa criança, mas devido aos fortes laços afetivos criados através da convivência, passou a ter real interesse na adoção, por considerar essa criança como um membro da família (BRASIL, 2016b).

Ainda menciona o PL $\mathrm{n}^{\circ}$. 5443/2016 que ao dar a oportunidade das genitoras manifestarem o interesse em entregar seus filhos para a adoção, elas mesmas terão a oportunidade de escolher quem irá cuidar/adotar seu filho, mesmo que não tenha vínculos de parentesco entre os pais biológicos e a família adotante. Muitos pais entregam seus filhos para a adoção por problemas financeiros e não terem condições de oferecer a subsistência necessária para a criação da criança, mas se preocupam em saber que a criança será bem cuidada pelas famílias que por eles foram elegidas (BRASIL, 2016b).

No entanto um grande mal pode estar sendo criado, devido ao fato de que poderão crescer ainda mais os números de venda e desaparecimento de crianças e adolescentes no Brasil. Nesse sentido uma organização traz dados alarmantes de crianças e adolescentes que podem estar movimentando o tráfico internacional, estando a pesquisa disponível na página virtual da Organização Desaparecidos do Brasil ${ }^{5}$.

Com o objetivo de agilizar o processo de adoção e dar mais garantias para direitos de crianças e adolescentes, a Lei n. 13.509/2017 trouxe algumas alterações importantes, que, no entanto, dependerão da estrutura do Poder Judiciário para que sejam postas em prática.

A lei fixa prazo para que o Ministério Público ingresse com a ação de destituição do poder familiar em 15 dias a contar do recebimento do relatório descrevendo a situação familiar. Ainda, quanto a realização de estudo social ou perícia, determina que seja realizada concomitantemente com a determinação da citação, que deverá ser realizada por Oficial de Justiça, o mais rápido possível, devendo a citação por edital ocorrer somente quando o oficial de justiça tenha tentado citar o requerido pessoalmente por pelo menos duas vezes (BRASIL, 2017).

Importante mencionar ainda que a lei refere que o prazo máximo para conclusão do procedimento será de 120 dias, cabendo ao juiz, no caso de notória inviabilidade de manutenção do poder familiar, dirigir esforços para preparar a criança ou o adolescente com vistas à colocação em família substituta (BRASIL, 2016a).

\footnotetext{
${ }^{5}$ Organização Desaparecidos do Brasil. Disponível em: <http://www.desaparecidosdobrasil.org/procuro-minhamae/trfico-internacional-de-crianas---mercado-bilionrio>. Acesso em 17 maio 2017.
} 
Possui, ainda, como como pressuposto quanto a possibilidade do Poder público preparar-se de maneira mais célere quando da colocação da criança e do adolescente em família substituta, tendo em vista que restou inviável sua manutenção em suas famílias originais. Traz medidas com relação ao estudo social ou perícia que são aplicados por equipe interprofissional ou multidisciplinar, tais medidas objetivam racionalizar o regramento quanto à sua realização ao ser determinado pelo juiz (BRASIL, 2017).

O novo texto legal também prevê a preferência na adoção para pessoas interessadas em adotar grupos de irmãos e crianças ou adolescentes com deficiência, doença crônica ou necessidades específicas de saúde (BRASIL, 2017).

Mais uma determinação legal é que o estágio de convivência tenha, no máximo noventa dias para adoções no Brasil, prazo que antes era estipulado livremente pelo juízo. E, para adoção internacional, o período fixado é de trinta a quarenta e cinco dias (BRASIL, 2017).

Assim, com o desenvolvimento do estudo foi possível verificar fatores que tem impacto no tempo dos processos de adoção e com isso, apontar possíveis soluções para otimizar tal tempo, especialmente por meio de projeto de lei já em andamento no Congresso Nacional e legislação recente.

\section{CONSIDERAÇÕES FINAIS}

O presente estudo teve como escopo principal demonstrar alguns dos motivos responsáveis pela morosidade dos processos de adoção no Poder Judiciário Brasileiro. Necessário se fez realizar um estudo aprofundado nas diversas questões que norteiam o instituto da adoção, que, como visto, é um instituto dos mais antigos e fez parte da cultura de muitos povos.

Pode-se observar que a adoção possui como principal finalidade poder oferecer um ambiente favorável para o desenvolvimento de uma criança e adolescente, a qual, por uma série de motivos, viu-se obrigada a deixar sua família natural. Crianças e adolescentes que passam pela dor emocional de um processo de destituição do poder familiar, precisam de acompanhamentos constantes, e, principalmente, sejam rodeados de muito amor e carinho, para assim esses infantes crescerem sem vestígios de traumas sofridos por essa fase tão difícil de suas vidas. 
Para o estudo aprofundado dos processos de adoção, necessário se fez analisar alguns institutos constitucionais. Foram estudados os institutos do devido processo legal e da razoável duração dos processos, sendo que se tratam de direitos fundamentais consagrados em diversos documentos internacionais de proteção e de promoção dos direitos humanos.

Depois de todo esse primeiro momento de conceituação e contextualização histórica do instituto da adoção, do devido processo legal e da razoável duração dos processos, é que fora aprofundado quanto a morosidade dos processos de adoção, que, como visto, existem muitos motivos que fazem perpetuar-se por um longo tempo essa morosidade processual e mesmo que sejam propostas medidas para dirimir o tempo de tramitação processual, necessário se faz um estudo aprofundado a fim de averiguar se realmente essas propostas irão surtir efeitos.

É possível apontar-se como principais motivações para tal período de tempo a necessidade de que ocorra a destituição do poder familiar e, com isso, a busca incessante para que a genitora seja ouvida ou para que a família biológica extensa possa receber tal criança e, a própria demora judicial, sem atendimento exato dos prazos previstos em lei, como por exemplo, o prazo extrapolado para juntada dos estudos sociais.

Esse último também leva a outra questão que diz respeito à estrutura do Poder Judiciário não estar capacitada para atender aos prazos e ao tempo previsto em lei, pois, na maior parte das vezes, faltam servidores para atender às demandas, agindo, então, por prioridades.

Muito se tem estudado quanto ao enorme desgaste que um processo de destituição do poder familiar traz às crianças, neste sentido busca-se, quem sabe, uma humanização dos profissionais envolvidos com esses procedimentos, que ao manusearem processos desta natureza não tratem como mero papel, mas sim a vida de um ser que está sendo decidida qual será seu destino, mas de nada adiantará que esses profissionais sejam humanizados se não for providenciado a colocação de mais profissionais para atender às demandas já existentes.

Pode-se dizer, pela análise acima, que as preferências e a demora no processo de destituição do poder familiar são dois fatores que impactam consideravelmente no tempo para adotar.

Por mais que se criem novas normas a fim de dar maior celeridade, ou que procure trazer menos desgaste emocional, tanto para os infantes, quanto para os interessados na adoção, faz-se necessário que essas normas sejam efetivamente cumpridas, e, para isso, faz-se necessário que haja sempre a supervisão de um profissional preparado para tanto. 
Nesse sentido, muito embora o ordenamento jurídico brasileiro preveja uma série de requisitos a serem observados no processo de adoção, tais preceitos devem ser cumpridos nos seus termos, de modo razoável e proporcional, dando mais celeridade nos procedimentos adotivos e, consequentemente, resguardar os interesses do adotando e analisar se o que está sendo feito trarão reais vantagens a este, bem como inseri-lo no ambiente familiar e, assim, dirimir o sofrimento decorrente de seu abandono.

Sem dúvidas o caminho para um processo ideal é muito longo e implica uma série de questões, que por muitas vezes faz com que as medidas não possam ser implementadas, e que por dado motivo está longe de ser obtivo um modelo de procedimento processual perfeito, mas tem-se que ter em mente que processos que envolvam crianças e adolescentes é de suma importância e merecem um tratamento muito especial, visto que referidos processos manuseiam os destinos destes infantes.

\section{REFERÊNCIAS}

ASSIS, Araken de. Duração razoável do processo e reformas da lei processual civil. 2. ed. Porto Alegre: Revista Jurídica, 2008.

BORGES, Alice Gonzalez. Duração razoável do processo administrativo e responsabilidade do Estado. Revista de Direito da Procuradoria Geral do Rio de Janeiro. ed. especial. 2012. Disponível em: <http://download.rj.gov.br/documentos/10112/915066/DLFE53906.pdf/REVISTAEDESP70.pdf>. Acesso em: 21 set. 2016.

BRAGANÇA, Renata Resende; PEREIRA JUNIOR, Antonio Alexandre. Crianças institucionalizadas: a demora na adoção. Revista UNINGÁ Review. Maringá/PR.Vol.23, n.3, pp.89-97. Jul - Set 2015. Disponível em: <http://www.mastereditora.com.br/periodico/20150902_105856.pdf>. Acesso em: 10 maio 2017.

BRASIL. Câmara dos Deputados. Projeto de Lei $\mathbf{n}^{\circ}$. 5443/2016. Acrescenta dispositivo à Lei $\mathrm{n}^{\circ}$ 8.069, de 13 de julho de 1990, que "Dispõe sobre o Estatuto da Criança e do Adolescente e dá outras providências". Autoria: Carlos Gomes Bezerra. 01 Jun 2016b. Disponível em: <http://www.camara.gov.br/proposicoesWeb/fichadetramitacao?idProposicao=2086233>. Acesso em 17 maio 2017.

Câmara dos Deputados. Projeto de Lei $\mathbf{n}^{\circ}$. 5850/2016. Altera a Lei $\mathrm{n}^{\circ}$ 8.069, de 13 de julho de 1990, que "Dispõe sobre o Estatuto da Criança e do Adolescente e dá outras providências". Autoria: Augusto Rodrigo Coutinho de Melo. 14 jul 2016a. Disponível em: <http://www.camara.gov.br/proposicoesWeb/fichadetramitacao?idProposicao=2092189>. Acesso em 17 maio 2017. 
. Conselho Nacional de Justiça. Provimento $\mathbf{n}^{\mathbf{0}} \mathbf{. 3 6 / 2 0 1 4}$. Dispõe sobre a estrutura e procedimentos das Varas da Infância e Juventude. 05 maio 2014. Disponível em: <http://www.cnj.jus.br///images/atos_normativos/provimento/provimento_36_05052014_070 52014134459.pdf>. Acesso em: 18 maio 2017.

\section{out}

Constituição (1988). Constituição da República Federativa do Brasil. Brasília, 5

out $1988 . \quad$ Disponível

em:<http://www.planalto.gov.br/ccivil_03/Constituicao/Constituicao.htm>. Acesso em: 29 maio 2016.

Presidência da República. Casa Civil. Subchefia para Assuntos Jurídicos. Lei no 10.406 de 10 de janeiro 2002. Institui o Código Civil. Brasília, 10 jan 2002. Disponível em: <http://www.planalto.gov.br/ccivil_03/leis/2002/110406.htm>. Acesso em: 29 maio 2016.

Presidência da República. Casa Civil. Subchefia para Assuntos Jurídicos. Lei No 13.105, de 16 de março de 2015. Código de Processo Civil. Disponível em: <http://www.planalto.gov.br/ccivil_03/_ato2015-2018/2015/lei/113105.htm>. Acesso em: 27 fev. 17.

Presidência da República. Casa Civil. Subchefia para Assuntos Jurídicos. Lei no 8.069, de 13 de julho de 1990. Dispõe sobre o Estatuto da Criança e do Adolescente e dá outras providências. Brasília, 13 jun 1990. Disponível em: <http://www.planalto.gov.br/ccivil_03/leis/L8069Compilado.htm>. Acesso em: 29 maio 2016.

Presidência da República. Casa Civil. Subchefia para Assuntos Jurídicos. Lei $\mathbf{n}^{\mathbf{0}}$ 12.010, de 3 de agosto de 2009. Dispõe sobre adoção; altera as Leis nos 8.069, de 13 de julho de 1990 - Estatuto da Criança e do Adolescente, 8.560, de 29 de dezembro de 1992; revoga dispositivos da Lei no 10.406, de 10 de janeiro de 2002 - Código Civil, e da Consolidação das Leis do Trabalho - CLT, aprovada pelo Decreto-Lei no 5.452, de 1o de maio de 1943; e dá outras providências. Brasília, 03 ago 2009. Disponível em: <http://www.planalto.gov.br/ccivil_03/_ato2007-2010/2009/lei/112010.htm>. Acesso em 10 maio 2017.

Presidência da República. Casa Civil. Subchefia para Assuntos Jurídicos. Lei $\mathbf{n}^{\mathbf{0}}$ 13.509, de 22 de novembro de 1990. Dispõe sobre adoção e altera a Lei no 8.069, de 13 de julho de 1990 (Estatuto da Criança e do Adolescente), a Consolidação das Leis do Trabalho (CLT), aprovada pelo Decreto-Lei $\mathrm{n}^{\mathrm{o}}$ 5.452, de $1^{\mathrm{o}}$ de maio de 1943 , e a Lei $\mathrm{n}^{\mathrm{o}} 10.406$, de 10 de janeiro de 2002 (Código Civil). Brasília, 22 nov 1990. Disponível em: <http://www.planalto.gov.br/ccivil_03/_ato2015-2018/2017/lei/L13509.htm>. Acesso em: 29 maio 2016.

BUENO, Cassio Scarpinella. Curso sistematizado de direito processual civil: teoria geral do direito processual civil. 6. ed. São Paulo: Saraiva, 2012.

CNJ, Conselho Nacional de Justiça. CNJ serviço: entenda o que é suspensão, extinção e perda do poder familiar. Disponível em: <http://www.cnj.jus.br/noticias/cnj/80757-cnjservico-entenda-o-que-e-suspensao-extincao-e-perda-do-poder-familiar>. Acesso em: 07 maio 2016. 
CNJ, Conselho Nacional de Justiça. Processos de adoção são mais lentos no Centro-Oeste e Sul. Acesso em: <http://www.cnj.jus.br/noticias/cnj/79750-processos-de-adocao-sao-maislentos-no-centro-oeste-e-sul>. Acesso em: 29 abr. 2017.

COELHO, Fábio Ulhoa. Curso de direito civil [livro eletrônico]: família, sucessões, volume 5. 1.ed. Editora Revista dos Tribunais. São Paulo. 2016.

CRUVINEL, Letícia Miguel; FALEIROS, Thaísa Haber. A razoável duração do processo como garantia constitucional e o possível cerceamento de defesa decorrente de sua aplicação. 2010.2 Disponível em: <http://www.publicadireito.com.br/conpedi/manaus/arquivos/anais/fortaleza/3923.pdf>. Acesso em: 16 maio 2016.

DIAS, Maria Berenice. Manual de direito das famílias. 8. ed. rev. e atual. São Paulo: Editora Revista dos Tribunais. 2011.

DIGIÁCOMO, Murillo. Questão do prazo na adoção. Realidade brasileira sobre adoção. Senado Federal. 2013. Disponível em: < https://www.senado.gov.br/noticias/Jornal/emdiscussao/adocao/realidade-brasileira-sobreadocao/questao-do-prazo-na-adocao.aspx>. Acesso em: 4 mar. 2017.

FARIA, Márcio Carvalho. A duração razoável dos efeitos: uma tentativa de sistematização na busca de soluções à crise do processo. Revista Eletrônica de Direito Processual - REDP. Volume VI. Periódico da Pós- Graduação Stricto Sensu em Direito Processual da UERJ. Patrono: José Carlos Barbosa Moreira. Rio de Janeiro. 2010. Disponível em: <file:///C:/Users/User/Downloads/7984-27947-1-PB.pdf>. Acesso em: 16 maio 2016.

FARIAS, Cristiano Chaves de; ROSENVALD, Nelson. Curso de direito civil. 6. ed. rev., ampl. e atual. Bahia. Editora JusPodivm. 2014.

FONSECA, Antônio Cezar Lima Da. Direitos da Criança e do Adolescente, Editora Atlas, 2011.

GONÇALVES, Carlos Roberto. Direito civil brasileiro, volume 6: direito de família. 7. ed. rev. e atual. São Paulo: Editora Saraiva. 2010.

GONÇALVES, Raquel Valenti. Adoção, reflexos do procedimento. 2009. 29f. Trabalho de Conclusão de Curso II - Pontifícia Universidade Católica do Rio Grande

do Sul. Porto Alegre. 2009. Disponível em: <http://www3.pucrs.br/pucrs/files/uni/poa/direito/graduacao/tcc/tcc2/trabalhos2009_2/raquel_ goncalves.pdf >. Acesso em 09 maio 2017.

GRANATO, Eunice Ferreira Rodrigues. Adoção: doutrina e prática. 2. ed. rev. e ampl. Curitiba. Editora Juruá: 2010.

GROSS, Marco Eugênio. Devido processo legal procedimental e ofensa reflexa à constituição soluções para superação de um dogma. Revista de Processo: RePro, v. 36, 
n. 193, p. 375-399, mar. 2011. Disponível em: <http://bdjur.stj.jus.br/dspace/handle/2011/81228>. Acesso em: 27 fev. 17.

KREUZ, Sérgio. Questão do prazo na adoção. Realidade brasileira sobre adoção. Senado Federal. 2013. Disponível em: https://www.senado.gov.br/noticias/Jornal/emdiscussao/adocao/realidade-brasileira-sobreadocao/questao-do-prazo-na-adocao.aspx>. Acesso em: 4 mar. 2017.

MEDINA, Paulo Roberto de Gouvêa. Direito Processual Constitucional. 5. ed. Rio de Janeiro: Forense, 2012.

MIGLIAVACCA, Luciano de Araújo; SOVERAL, Raquel Tomé. A Efetividade dos Direitos Fundamentais no Âmbito Administrativo e a Aplicabilidade do Princípio da Razoável Duração do Processo. 2015. Disponível em: $<$ file:///C:/Users/User/Downloads/Dialnet-

PelaEfetividadeDosDireitosFundamentaisNoAmbitoAdmi-5526356\%20(1).pdf>. Acesso em: 02 Jun 2017.

MORAES, Alexandre de. Direitos Humanos Fundamentais. Teoria Geral. Comentários aos arts. $1^{\circ}$ a $5^{\circ}$ da Constituição da República Federativa do Brasil, doutrina e jurisprudência. 9. ed. São Paulo. Editora Atlas. 2011.

NEVES, Daniel Amorim Assumpção. Manual de direito processual civil. 5. ed. São Paulo: Metodo, 2013.

NICOLITT, André. A duração razoável do processo [livro eletrônico]. 1. ed. em e-book baseada na 2. ed. impressa. São Paulo. Editora Revista dos Tribunais. 2014.

NUNES, Marcelo Guedes (Coordenador) [et al.]. Processos relacionados à adoção no Brasil: uma análise sobre os impactos da atuação do Poder Judiciário. 247 p. - (Série Justiça e Pesquisa). Brasília: Conselho Nacional de Justiça, 2015. Disponível em: <http://www.cnj.jus.br/files/conteudo/destaques/arquivo/2015/07/8aab4515becd037933960ba 8e91elefc.pdf>. Acesso em 10 maio 2017.

PORTANOVA, Rui. Princípios do Processo Civil. 6. ed. Porto Alegre: Livraria do Advogado, 2005.

RAMOS, João Gualberto Garcez. Evolução histórica do princípio do devido processo legal. Disponível em: http://egov.ufsc.br/portal/sites/default/files/anexos/32382-38999-1PB.pdf>. Acesso em: 1 mar. 2017.

SANTOS, Vívian Cruz dos. O princípio da razoável duração do processo. 2014. $27 f$. Artigo Científico para obtenção do título de Pós- Graduação - Escola da Magistratura do Estado do Rio de Janeiro. Rio de Janeiro. 2014. Disponível em: <http://www.egov.ufsc.br/portal/sites/default/files/viviancruzdossantos.pdf >. Acesso em: 08 maio 2017.

SANTOS, Ana Maria Augusta dos. Acolhimento Institucional de Crianças e Adolescentes: Mudanças na História Brasileira. Disponível em: http://www.cress- 
mg.org.br/arquivos/simposio/ACOLHIMENTO\%20INSTITUCIONAL\%20DE\%20CRIAN\% C3\%87AS\%20E\%20ADOLESCENTES\%20MUDAN\%C3\%87AS\%20NA\%20HIST\%C3\%9 3RIA\%20BRASILEIRA.pdf. Acesso em 05 out. 2016.

SARLET, Ingo Wolfgang. A eficácia dos direitos fundamentais: uma teoria geral dos direitos fundamentais na perspectiva constitucional. 10. ed., rev., atual e ampl. Porto Alegra. Editora Livraria do Advogado. 2009.

SCHREIBER, Elisabeth; MANGUEIRA, Renata Torres da Costa. A violência intrafamiliar na infância: uma abordagem jurídica e psicológica: estudo multidisciplinar. Editora Arana. Porto Alegre. 2014.

SOUZA, Graziele Bernardi. A morosidade no processo de adoção no Brasil. 2016. 61f. Monografia apresentada para obtenção do título de Bacharel em Direito - Universidade do Tuiuti do Paraná. Curitiba/PR. 2016. Disponível em: <http://tcconline.utp.br/media/tcc/2016/09/A-MOROSIDADE-NO-PROCESSO-DEADOCAO-NO-BRASIL.pdf>. Acesso em 10 maio 2017.

THEODORO JÚNIOR, Humberto. Direito fundamental à duração razoável do processo. Belo Horizonte. 2008. Disponível em: <http://www.animaopet.com.br/pdf/anima2/Humberto_Theodoro_Junior.pdf>. Acesso em: 16 maio 2016.

VENOSA, Sílvio de Salvo. Direito civil: direito de família. 7.ed. 2. reimpr. Editora Atlas. São Paulo. 2007.

9. ed. Editora Atlas. São Paulo. 2009.

WALD, Arnoldo; FONSECA, Priscila M. P. Corrêa da. Direito civil: direito de família, vol. 5. 17. ed. reformulada. Saraiva. São Paulo. 2009. 